Please do not remove this page

RMIT

UNIVERSITY

\title{
Take a photograph: Teacher reflection through narrative
}

Lemon, Narelle

https://researchrepository.rmit.edu.au/esploro/outputs/9921863861601341/filesAndLinks?institution=61RMIT_INST\&index=null

Lemon, N. (2007). Take a photograph: Teacher reflection through narrative. Reflective Practice, 8(2),

177-191. https://doi.org/10.1080/14623940701288982

Published Version: https://doi.org/10.1080/14623940701288982

Repository homepage: https://researchrepository.rmit.edu.au

(c) 2007 Taylor \& Francis

Downloaded On 2023/04/27 01:03:11 +1000

Please do not remove this page 


\section{Citation:}

Lemon, N 2007, 'Take a photograph: Teacher reflection through narrative', Reflective Practice, vol. 8 , no. 2, pp. 177-191.

\section{Take a photography: Teacher reflection through narrative}

\section{Summary:}

This paper is an introduction to the place of narrative inquiry in relation to teacher professional development and reflection. Connections are made with photography (visual narrative) as a tool for reflective practice with a discussion accompanying literature that addresses the use of photography for the first time to trigger and assist in the development of professional practice. Consideration is made to photographs being taken by colleagues, self or students to provide a different perspective of learning occurring in the classroom accompanied by the generation of questions, goal setting and the reinforcement of self-assessment and self-monitoring.

\section{Biographical Detail of Author:}

Narelle Lemon has over ten years teaching experience in both the music and generalist primary classroom and the Arts secondary settings in Australia. Narelle currently works with pre-service teachers in The Faculty of Education at The University of Melbourne. She presents regularly both nationally and internationally in areas of music education, coping skills, visual narrative and reflective practice. She is currently completing her doctoral thesis in the Faculty of Education at The University of Melbourne on the topic of visual narrative as a form of reflection in the early childhood classroom.

FINAL EDITS_Take a photography, N.Lemon (2007) The University of Melbourne, page 1 


\title{
Take a photography: Teacher reflection through narrative
}

\author{
Narelle Lemon \\ n.lemon@unimelb.edu.au \\ Faculty of Education \\ The University of Melbourne, Australia \\ 2006
}

\section{Capturing an image: An introduction to Narrative Inquiry}

'A narrative offers an opening into others' meaning making processes'

(Bager-Charleson, 2004, pp1)

Clandinin \& Connelly (2000) liken narrative inquiry to a soup (pp 155) where your imagination leads you to a rich steamy soup filled with various chunks of vegetables, rice and noodles, spiced with herbs, salt and pepper. Then imagine another soup of slightly different ingredients, amounts, sized chunks, and spices. Through looking at the metaphor of soup Clandinin \& Connelly (2000) go onto to say that as with different soups comes also the different ingredients that make a narrative. The metaphor of soup becomes a way to imagine the 'complexity in the form of narrative inquiry research' (Clandinin \& Connelly, 2000, pp156).

Various interpretations and definitions have been referred to in the literature addressing narrative inquiry. Key words such as memory, fact and fiction, interpretation, story, history, context, image, metaphor, situation, continuity, interaction and view of experience often appear in the literature (Dewey, 1929; Bach, 1998; Clandinin \& Connelly, 2000; Bach, 2001; Florio-Ruane, 2001). Descriptive Narrative and Explanatory Narrative (Polkinghorne, 1998) have been referred to in an attempt to clarify further the role of narrative inquiry. Descriptive Narrative has a purpose of producing an accurate description of individual or group's accounts of events in their life, while in Explanatory Narrative the interest lies with the connection between events in a casual sense and to provide the necessary narrative accounts that supply the connections.

Narrative inquiry is a process (narrator or participant telling a story) and a product (the narrative or story). People tell stories. A story is an example of a narrative. A story is always a narrative, but narrative structure is not limited to story. By using the two interchangeably or fitting it to a specific context, you can capture the experiential quality of "telling a story." A particular way of thinking or knowing and a framework for telling - that is narrative — is revealed at the same time (Kramp, 2004).

Time and place are important for narrative inquiry as they assist in providing knowledge of a rich ethnography. Narrative inquiry always has a purpose, although focus may develop and change over time. Each story has a setting in time and place. Each story has a beginning, middle, and ending, although not necessarily presented in that order as it is told (Kramp, 2004, pp109). Narrative boundaries expand and are permeable. Researchers'

FINAL EDITS_Take a photography, N.Lemon (2007) The University of Melbourne, page 2 
personal, private and professional lives flow across the boundaries into the research site though not with the same intensity as those of the participants (Clandinin \& Connelly, 2000). The result of this flow and relationship is that there is a virtually endless list of life experiences that might be frequently introduced into field texts of value to the inquiry. Connections are made to the narrative through life experiences from participants, researchers, and audiences with links to the inquiry- stories are shared.

Narrative inquiry opens up to the reading audience a deeper understanding or view of life in familiar contexts while also providing familiarity to those strange situations (Clough, 2002). Telling a story through narrative can reveal a snapshot of inner conflict, inner mental state or emotional states in particular environments involving an individual or others and their subsequent relationship. Narratives can be dramatic and they reveal the narrator as (s)he wants others to experience the story, thus having moral or evaluative force (Florio-Ruane, 2001).

Narrative inquiry cannot be reduced to a formula or an itemized listing of component parts (Kramp, 2004, pp109-110). A narrative connects events, actions, and experiences and moves them through time (Daiute \& Lightfoot, 2004; Kramp, 2004) with structuring and framing relationships constructing these. The narrative is offered for interpretation, where the researcher can construct meaning where perhaps there was none, or where it was unknown. The participant's story compels you to consider what typically complicates research - a particular voice "telling about" a particular experience (Kramp, 2004, pp110). The narrative told is not merely a listing of events and actions, nor simply a series of anecdotes, but rather, it is a perspective that enables you as the researcher to see differently, to move between the particular and the generic, aware of what each says to enrich the other. Narrative inquiry generates what careful observation cannot-a way of understanding by being open to the stories individuals tell and how they themselves construct their stories and thus themselves.

Narrative inquiry has been used extensively in social sciences (Clough, 2002; Moss, 2003). In educational settings narrative inquiry can take on the role where stories provide a means by which the truth, that sometime cannot otherwise be told, are uncovered (Bach, 2001; Clough, 2002) or might otherwise not be able to be reported using other types of data collection. The opportunity is offered for researchers and practitioners to describe exactly what happens in the classroom or educational institution, thus 'providing the protection of anonymity to the research participants without stripping away the rawness of real happenings' (Clough, 2002, pp 8).

\section{Take a picture: The role of Visual Narrative}

'Images created with photographs thicken ways of seeing'.

(Bach, 2001, pp 1)

'Visual narrative enables the researcher to work in a number of ways' (Moss, 2003, pp5) where images can be collected in the forms of drawings, photographs, video and digital

FINAL EDITS_Take a photography, N.Lemon (2007) The University of Melbourne, page 3 
photography. Photographs and visual narrative have been used for the construction of social narratives for centuries (Bach, 1998; Clandinin \& Connelly, 2000; Moss, 2003) archives at museums, family history collections, or even memory boxes. Photographs mark a memory in our time, a memory around which we 'construct stories' (Clandinin \& Connelly, 2000, pp 114) and that show fragments that have no specific beginning or ending.

Visual narrative research draws upon the use of photography to evoke memory in our lives, a memory that can be used to construct and reconstruct stories. Photographs can be used as a way to preserve the appearance of an event or a person or as a metaphor of an experience that has been closely associated with the initial idea or relationship (Bach, 1998; Bach, 2001). Visual narrative makes visible the different parts or narratives of a story as well enabling opportunity to explore different positions within a dynamic environment or situation.

Visual narrative, however, is not complete without narrative support through dialogue and language. Photographs do not themselves preserve meaning (Wood, 2000; Bach, 2001); they offer appearances for which a narrator can make us understand. Photographs by themselves do not narrate, they do provide prospect to reflect and grow from our experiences.

The use of visual narrative as providing an opportunity to 'photograph the world inside and outside of school' has been discussed in relation to working with students in an educational setting (Bach, 2001, pp 1). Throughout these inquires the curiosity of the "evaded" curriculum comes to the forefront; that is the experiences that are not seen and that can be ignored in both students' and teachers' lives. An opportunity is created where learning and meaning can be connected to the images and where relationships connect to sub cultures (Bager-Charleson, 2004).

Visual narrative in education can be quite powerful - photographs, paintings, drawings and images of student work are used frequently. They can be a tool used for displays in school classrooms and corridors, promotion of schools on billboards out the front of the school entrance or on a major highway, in school documents to prospective parents or can be seen each week in newspapers with advertisements for employment opportunities for teachers. The message sent across to the audience each time is of an insight into the type of experiences a child may have in the classroom at a particular school. But visual narrative is also a tool for teacher to reflect on what is happening in their classrooms, one that is often easily forgotten.

\section{Reflective practice as a teacher}

'It is equally important for teachers (as learners) to monitor their own performance as it is for children. Not only should teachers reflect on their own teaching and learning, they must be able to make the process and reasons for reflecting explicit to their students'.

FINAL EDITS_Take a photography, N.Lemon (2007) The University of Melbourne, page 4 
Teacher reflection, or reflective practice, has been justified on moral grounds as a responsibility for effectiveness (Wilson \& Wing Jan, 1993; Zeichner, 1994; Brookfield, 1995; Stronge, c2002; Young, 2003), as a means of achievement for prescribed practices (Zeichner, 1994; Jay, 2003), and as a means toward emancipation and professional autonomy (Calderhead, 1989; Loughren, 1996; Jay, 2003).

Reflective practice has sparked some interesting discussions in the past decades. Terms such as reflective teaching, reflective practitioner, action research, inquiry-orientated teacher education, teacher as decision maker, teacher as problem solver and teachers-asresearchers have been associated with reflective practice (Zeichner, 1994) particularly in the field of education. The processes of teacher reflection and the relationship between thinking processes, teacher development and reflective practice have also been at the centre of discussion resulting in emerging variations and some confusion in theory; Zeichner (1994) reports that everyone has a varying version of reflective practice in teaching.

Concepts of teacher reflection vary in dimensions (Calderhead, 1989; Brookfield, 1995) with relation to process of reflection (reflection in action, curriculum relevance), content of reflection (own values, educational theory), preconditions of reflection (attitude, context in which reflection is carried out), the product of reflection (effective teaching, values, and practice).

Grimmett et al (1990) began to define reflective practice in terms of the differences between what was being reflected upon, how the reflective process was engaged, and the purpose of reflection. This theory was then analysed further to identify three conceptual orientations, they being, reflection as instrumental mediation of action (where knowledge is used to direct practice), reflection as deliberating among competing views of teaching (where knowledge is used to inform practice), and reflection as restructuring experiences (where knowledge is used to help teachers transform practice).

Literature available also reports that reflective practice seeks to engage teachers with one another in thinking about the purposes and consequences of their work (Wilson \& Wing Jan, 1993; Zeichner, 1994; Brookfield, 1995). It is also evident that reflective practice is not something that teachers do only during undergraduate training or for a specific task, rather an ongoing method of reflective inquiry into individual programs, activities, and classroom behaviour; where reflective practice benefits both the students and teacher with change for effective teaching practice (Wilson \& Wing Jan, 1993; Zeichner, 1994; Brookfield, 1995; Stronge, c2002).

Although some theorists (Zeichner, 1994; Brookfield, 1995) have implied that there are varying varieties of reflective practice in teacher education (academic version, social efficacy version, developmentalist version, social reconstructionist version, and generic version), there is no doubt, however, among academics that reflective practice

FINAL EDITS_Take a photography, N.Lemon (2007) The University of Melbourne, page 5 
incorporates the process of collecting information in all forms, analyzing the information to deepen understanding, and on the basis of that understanding, reviewing and planning for change and improvement. From this reflective teachers face the challenge of truly seeing themselves and their teaching, consequently improving the quality of a work.

Effective teachers are reflective practitioners. In association with professionalism and effective teaching, reflective practice is often cited as an important part of the teaching process (Stronge, c2002). Effective teachers portray themselves as students of learning (Gawehen, 2003) with continuous professional development, self-evaluation and selfcritique as with reflective practice as a key learning tools (formally or informally).

As reflective practitioners, effective teachers continually analysis the impact of their teaching and professional beliefs have on their students, colleagues and the wider school community. While doing this an effective teacher will also look at how their own educational, social, and cultural experiences helped shape these beliefs and values and their approach to teaching and in turn their assumptions of education as a whole.

Reflective practice is a rewarding practice and has great impact on the quality and effectiveness of teaching professionalism, methodology, and knowledge, having at the very least, an impact on you as a learner. Reflection in teaching is a learning process for educators where they gain knowledge from own experiences; 'if teachers question their actions, reconsider their knowledge and understanding in the light of experience, they can use this to shape the way they approach helping their students to learn' (Loughren, 1996, p 6).

\section{Opening up possibilities of learning from each other}

Researchers who have adopted narrative methods have found them particularly useful for addressing the unmet challenge of integrating culture, person and change - a challenge that has been especially acute in the last quarter century.

Daiute \& Lightfoot, 2004, pp viii

To be able to tell your own story as a teacher along side those stories of the students allows for an interlocking of understandings. Stories imitate life and present an inner reality to the outside world while at the same time they shape and construct the narrator's personality and reality. We know and discover ourselves, and reveal ourselves to others, by the stories we tell (Lieblich, Tuval-Mashiach \& Zilber, 1998, pp 7).

By examining narratives, both my own and those of the early childhood children I have worked with, the appeal of examining something of interest, our learning, the learning of both myself as the teacher and that of the children, becomes evident. Daiute, \& Lightfoot (2004) explore and reiterate this in their work through stating narrative provides a unique insight into a range of multiple interconnecting forces that enlighten relations between self and society. Narrative inquiry is appealing because of its interpretative tools and how they are designed to examining phenomena, issues, and peoples loves holistically. Narratives allow for the teacher or teacher researcher to work with the natural voice

FINAL EDITS_Take a photography, N.Lemon (2007) The University of Melbourne, page 6 
where narrative discourse and metaphor are excellent contexts for examining social histories that influence identity and development while allowing for the incursion of value and evaluation into the research process.

Narrative inquiry, and its use, is developing within educational settings as it is a virtual process that stimulates and motivates life, organizing it and allowing for a view of life course (Daiute, \& Lightfoot, 2004). In turn development is a narrative process as it not only charts the journey but it also embodies life categories, events, moral judgments and motivations. Identity changes can be triggered through flash backs (Daiute, \& Lightfoot, 2004) or through subtle cues arsing from actions performed during the collection process (Sarbin, 2004) or telling of the stories. Literature of developmental scholars often refers to the personal journey that can be taken through narratives that assists in new ways of thinking (Bruner, 1990; Daiute, \& Lightfoot, 2004; Sarbin, 2004) and the development of self (Daiute, 2004; Lightfoot, 2004; Neslon, 2004).

In seeing photographs and listening to the narratives the world of learning and teaching is explored. One learns from themselves and from others (Berger, 1980; Spence, 1986; Clandinin \& Connelly, 2000; Bach, 2001; Bager-Charleson, 2004).

When used properly, photographs and the narratives can provide teachers with a key to discovering identity and understanding. Both in its real and historical stance as Lieblich, Tuval-Mashiach \& Zilber (1998, pp 8) discuss, with reference to peoples being 'meaninggenerated organisms'. Individuals construct their identities and self-narratives from building blocks in their common cultures, above and beyond their individual experiences. In looking at this with a constructionist approach, individuals construct self-image within an interaction and according to a specific interpersonal context. It could be said that through studying and interpreting narrative, the research can access not only the individual identity and its systems of meaning but also the teller's culture and social world (Richardson, 1990; Lieblich, Tuval-Mashiach \& Zilber, 1998).

\section{Narrative inquiry and visual narrative as a tool for teacher reflection}

'Such a shift in the ways we think about teacher, learner, and knowledge informs and potentially transforms teacher education, particularly as teachers learn about culture of narrative inquiry'.

(Florio-Ruane, 2001, pp 154)

The use of narrative inquiry in education as a source for teacher reflection and learning is growing where visual or text forms provide the opportunity for teacher support networks, increased collaboration with colleagues, and documentation of own learning within the educational context (Fredidus, 1998; Verhesschen, 1999; Florio-Ruane, 2001; Johnson, 2001; Moss et al, 2004).

FINAL EDITS_Take a photography, N.Lemon (2007) The University of Melbourne, page 7 
In narrative inquiry teachers learn to challenge the "take for granted" stance which can often go unnoticed in the learning environment. Narrative inquiry allows for the teacher to set up a classroom that challenges both him/herself and the students. New ways of learning are explored while engagement is maintained (Diekelmann, 2005).

In looking more closely at the potential narrative inquiry has for educators, as professional teachers and learners, many come to mind - the journey of enhancing understanding in what has been happening, and to learn how experiences might be shared with others teachers and with students are powerful tools for personal and professional development. Teachers often talk about their practice but don't regularly see their practice (Schwarz, 2001). Through exploring this option of documenting, visually or through supported text, practitioners open themselves up to learning experiences that tend not to be readily available in their usual work and staff development (Florio-Ruane, 2001).

For the teacher visual narrative can reveal inner conflict or self-revelation (Florio-Ruane, 2001; Bach, 2001) yet a consistent visual metaphor that displays aspects of personal growth (Johnson, 2001) can be created. Teachers could approach visual narrative in the same ways as a journey unfolding in their own learning experiences (Bach, 1998; Fredidus, 1998; Schwarz, 2001).

Images can represent life or learning as it happens. They represent and suggest a visual representation similar to that of journal entires, artefacts and field notes (Bach, 2001). In using visual narrative in the learning environment we can be given an opportunity to evoke memories where as Bach discussed 'a memory around we construct and reconstruct life stories' (2001, pp7). Visual narrative research makes visible different parts or stories that can then be later looked upon, just as photographs are used in the historical or family history sense. Most of all it enables us to look at a scene in our lives with different perspective, transformation of fixed memories is available (Bach, 2001). Photographs can allow us to learn, reflect and grow from our experiences.

We, as teachers, can learn from our photographs in the classroom as they enable us to come to terms with our experiences, positive or negative. They are indicators of celebrations, personal achievements, actions and interactions. Photos can assist us in exploring reoccurring stories (Spence, 1986; Bach, 2001). Each time we look at a photograph we have the opportunity to view it through maturing eyes, to see ourselves differently where we give ourselves the opportunity to learn and grow.

Ultimately in the classroom we want to create a learning environment that challenges, motivates and engages learners in meaningful learning and relates to the real world. As teachers, we are learners too, don't we want to have the same approach to our own learning? In using photographs, whether they be colleague, student or self taken, the narrative inquiry journey begins that can incorporate learning challenges, motivation, engagement, and asking questions about yourself as a learner. The camera can be seen as a tool that ignites inquiry into our own practice and promoting self awareness, self

FINAL EDITS_Take a photography, N.Lemon (2007) The University of Melbourne, page 8 
monitoring, reflective and reflexive practice while producing questions and answers and perhaps more questions towards the type of teacher and learner we want to be (see chart 1.1).

Chart 1.1: Graphic representation of teacher using photographs to look at own practice.

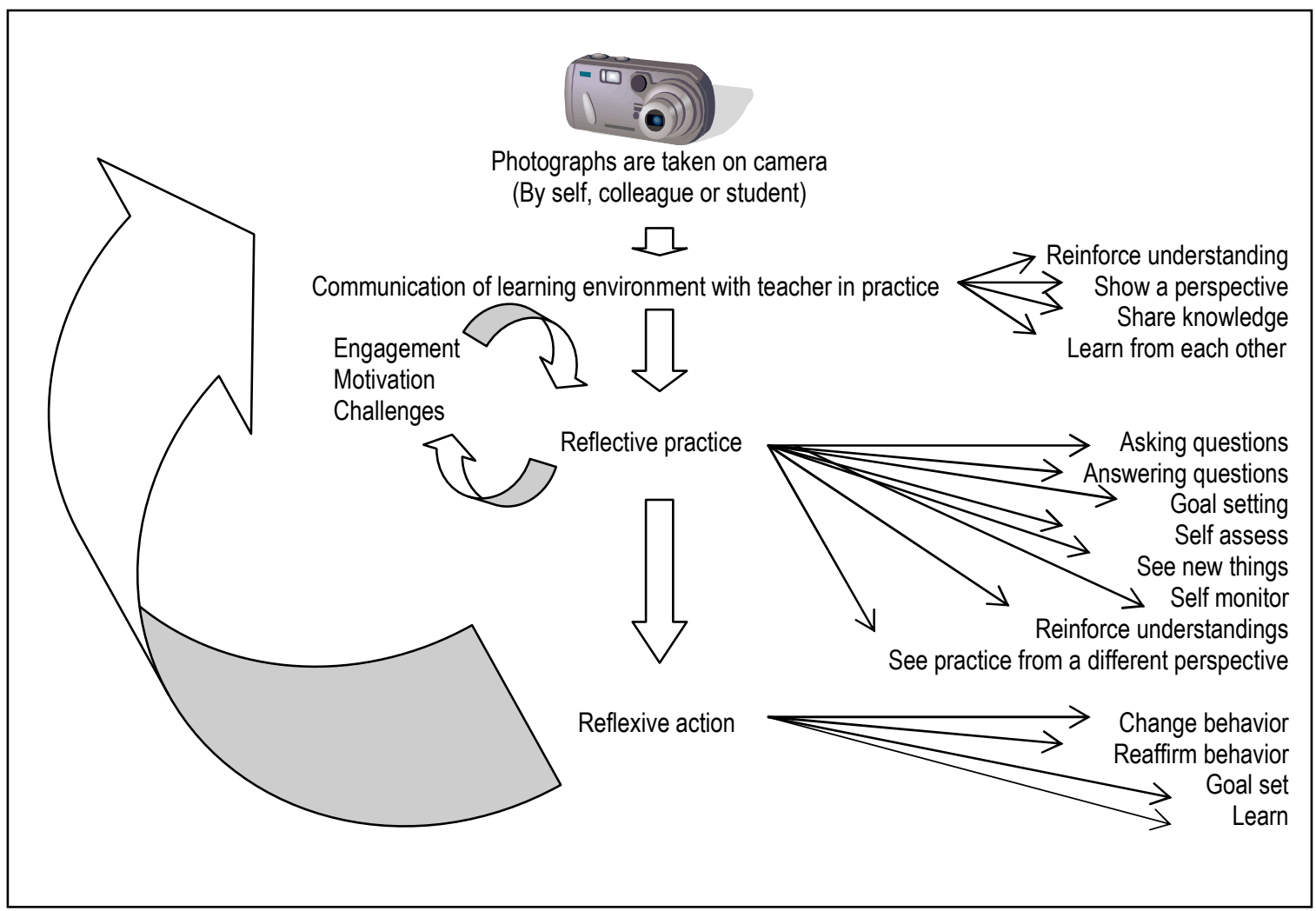

\section{The narrative journey as a teacher - personal reflection}

In exploring a narrative journey for the first time, many questions have been generated what is the power the photographs have in communicating the story of the classroom? What impact does my reflection on my practice via photographs have on the students learning? How will this impact the relationships within the classroom? How will my learning grow? What will my colleagues think? What will happen over time if I continue to reflect on my practice via photographs? What stories am I communicating? Could I use visual narrative as an ongoing method of reflective practice?

For me the photographs have shown a personal journey, one of professional development and growth. They have been a tool for my own reflection, student reflection, parent reflection, and discussions with colleagues. They have also been a constant reminder of how I have grown in my approach to teaching music, which has had an impact not only on the classes photographed but also classes I taught at other levels in the primary school extending into secondary level.

FINAL EDITS_Take a photography, N.Lemon (2007) The University of Melbourne, page 9 
The beginning of 2004 marked a new direction for my teaching career - I ventured into the early childhood classroom as a music specialist. Having previously taught music at a secondary level the change was one of a need for a new direction, personal development and looking at the whole picture of music education, which was supported with encouragement by the school I had been teaching at. I needed something new and I was being provided with an opportunity to explore my thoughts on teaching, learning, and the role of music education. I was also taking a big step in being able to look at myself as a teacher - could I teach 3 year olds as effectively as 13 or 15 year olds? Will I be able to relate to them? Will I be able to engage them? Am I a good teacher? Can I do this?

In all of my new teaching experiences I had never encountered more openness to collegiality than I did at this school. The principal would visit my classroom unannounced most days to "see how I was going". In the past at secondary schools the only time I saw the principal near a classroom was if someone was going to be yelled at. Fellow teaching staff were extremely encouraging, openly offering suggestions, strategies, and even resources to make my transition from secondary to primary easier. The early learning three-year-old teacher was one of my first colleagues who provided a new opportunity for me - she emailed me five photos (see below) of a music class with her children during the first week of school. A gesture of good will and something she thought I would like. The photos were all of that and more; they became the tool that generated a new direction in reflective practice.
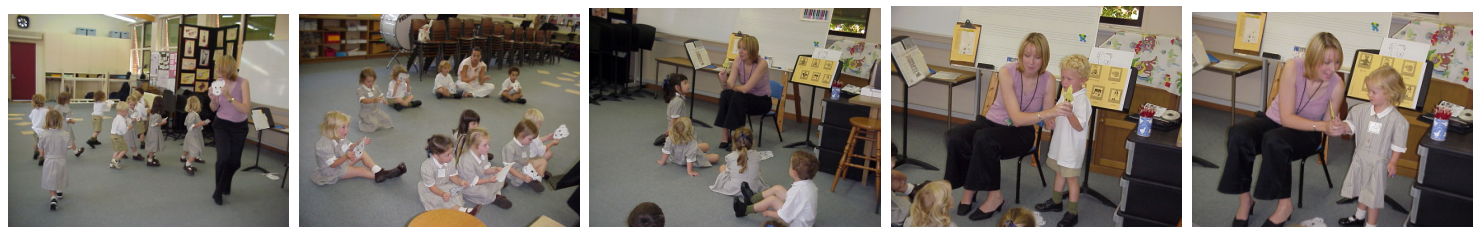

These photos triggered a reflective journey for me - one where I was seeing myself in the classroom environment for the first time. My relationship with the children was obvious, as to were the types of activities that were effective, and the reactions by the class as a whole and individual students. I had never seen myself like this. It was confronting. But it was motivating, rewarding, and it stimulated me to look further into the methods of using photographs for my professional development and as a method to reflect on my practice and what was happening in the classroom.

Reflection extract (February 2004):

This was the first lesson in which I introduced props to our music lesson. With the children having only been at school for a number of weeks, and being aware of adjustment to expectations and structure of lessons, I wanted to set myself the challenge, and for as much as the children, to be able to work with props to enhance our learning experiences. For the children to be able to use bear faces while we went on a 'bear hunt' was exciting. Many requests for "can we do it again" were rewarding for us all, and gave me the feedback of success. The 3-year-old classroom teacher was worried that the children wouldn't be able to be responsible with the bear faces. With clear instructions for the care of the bear faces, the children were able to respond well to the incentive that the bear faces would be used again and they would be able to take them home to show family and

FINAL EDITS_Take a photography, N.Lemon (2007) The University of Melbourne, page 10 
friends after the next lesson. I have enjoyed seeing myself in action with the children through the photographs. I can see how I am interacting with the children from a different perspective. I have been conscious of using the music room space productively where the children feel safe to explore their reactions to music and activities we do. It was a challenge I set myself to be able to introduce the props successfully and to be able to use them effectively to enhance engagement and enjoyment levels while developing music (listening, responding, singing, movement like a bear to the beat, sound effects) and gross motor skills (walking, stamping, following and making bear like actions). The children enjoyed the props and I now feel comfortable with my initial feelings of intruding them to continue using them in the learning environment.

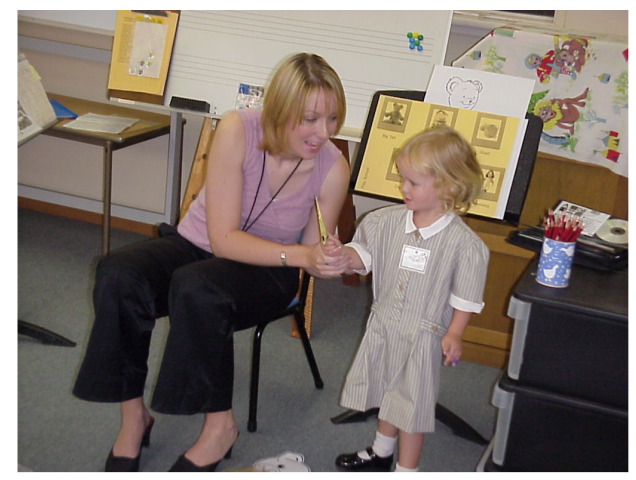

Reflection extract (February 2004):

I want to set the aims of working with children one on one to develop confidence, trust and to focus on individual needs while involving the whole class. I like the idea of introducing a new element to the lessons (finger puppets) and having individual children demonstrate key concepts (in this case the use of the puppet and movement to the beat of the music while singing the familiar words). The children watching on the floor join in while having a peer model the actions. Those children watching are just as excited to watch a peer as the child who is working with me one on one. The concept of peer support and appreciation is developing as well; I want to continue to explore and develop this in the class.

Visually documenting learning relationships within the classroom is powerful. Through working collaboratively with the three-year-old teacher, we had an understanding where photographs that were taken during music classes would be forwarded to me for the use of professional reflection. Communication within the classroom was occurring where different perspectives were being considered accompanied by the sharing of knowledge and understanding. In the process of learning from the photographs questions asking began to occur - When looking at the photos what do I see? What is the story? Whose story are the photographs? Who is making the picture? Whose gaze contacts the image? Who listens to the story told about the image? Who is talking? Are the people in the image the storytellers? Is the photographer the storyteller? Is the interpreter of the image the storyteller?

In the cycle of goal setting, self-assessment and self-monitoring, engagement levels along with motivation and the sense of a rewarding challenge were being associated with more questions - Could these photos be also used as tools for other colleagues? Was it

FINAL EDITS_Take a photography, N.Lemon (2007) The University of Melbourne, page 11 
possible that the method I was using for my own professional development could be a fantastic and rewarding method for fellow teachers? Followed by more questions - If other teachers look at the photos, what do they see? Do teachers naturally compare their work to what they see in the photos? Photos don't lie, are they too revealing? Would the photos initiate competitiveness amongst staff? Would colleagues feel exposed? How do teachers feel when others are looking at photos of themselves in a classroom?

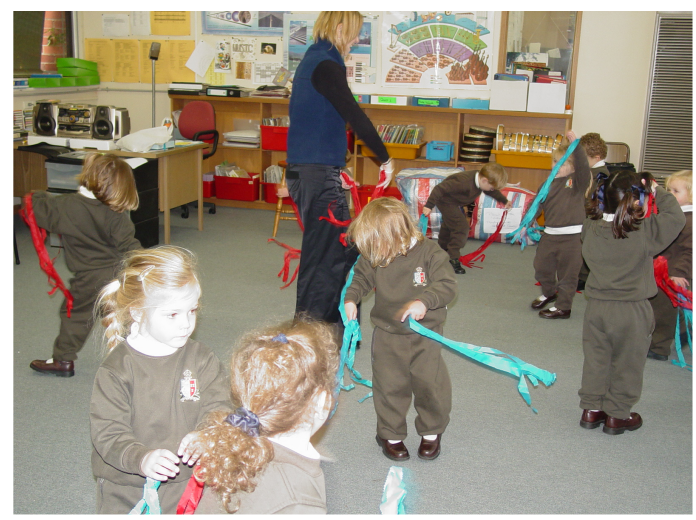

Reflection extract (March 2004):

I saw a colleague at another school use ribbons to add variety to movement. Can I use them in my program? Do they have a place? What will the children think? Will they be able to use them effectively? I spent a weekend making the ribbons, cutting the fabric and attaching them to soft hair elastics, and within 2 minutes of using the ribbons I knew they were a success. The photo reveals the enjoyment the children experienced. The natural inquiry of the shapes the ribbons made, the sound they made, the feeling they gave when using and if they brushed over your face was evident with the children actions and comments, "can I take mine home?" To be able to see this image allowed for an enhancement of what I felt when amongst the children exploring the ribbons, a different perspective and one that supports further exploration of using the ribbons to respond to music and develop gross motor skills.
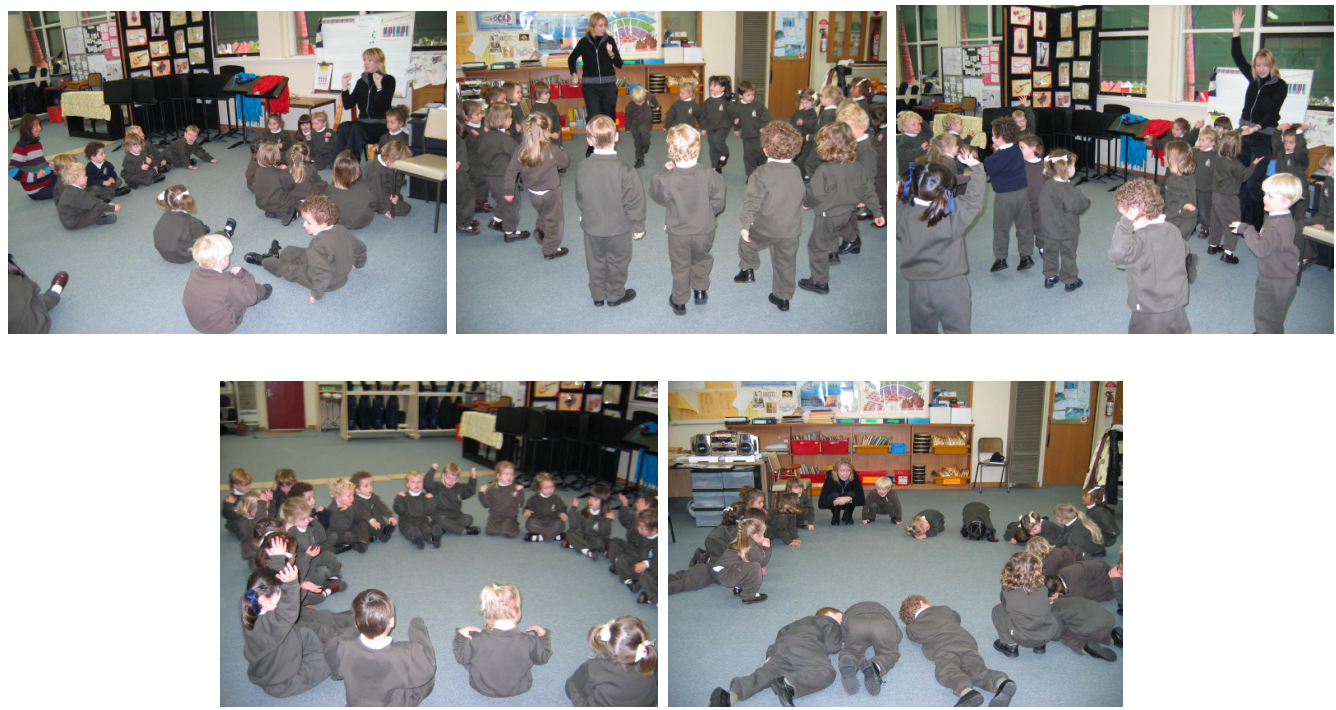

FINAL EDITS_Take a photography, N.Lemon (2007) The University of Melbourne, page 12 
Reflection extract (June 2004):

I'm enjoying the confidence I am establishing in using space in the music room in different ways. I feel I'm succeeding more in providing opportunities for the children to explore movement and action to songs in different ways. These photos offer a perspective that allows me to see who and how the music is being explored and responded too. Some questions have come up for me and I want to follow up on observing a few children further to make sure they are understanding and exploring the music fully. Are these children still developing? Does more individual focus need to be made? Are the children following the scaffolding being offered to them?

Throughout this investigation questions have arisen about the nature of visual narrative and how to analyze and evaluate the data. To another colleague, teacher or student a visual or photograph is just not enough; there can be varying interpretations of a photograph:

How do you interpret the photos?

What methods of analysis are available?

Do teachers naturally compare similarities and differences to their own practice?

Do teachers want to see themselves in a photograph?
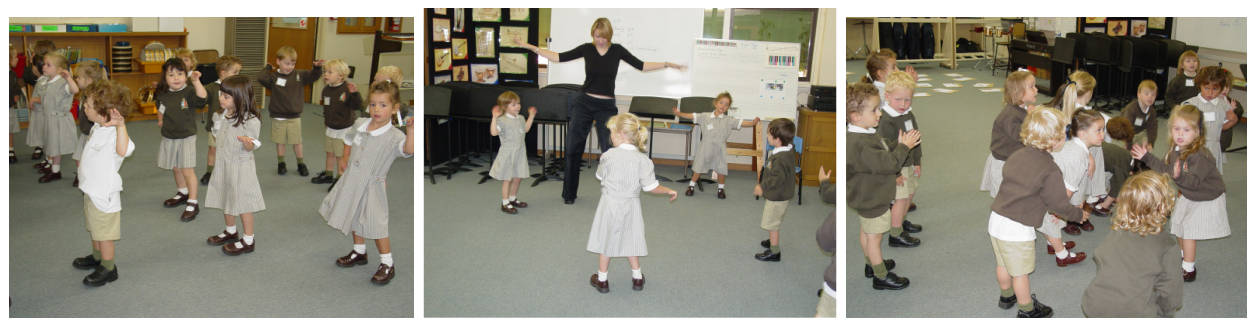

Reflection extract (March, 2004):

I wonder what the classroom teachers would think of these photos? What would their perspective be? What insights could they give that would help me? Or what judgments would be made? What message or story are these photos giving to someone who hasn't experienced 3 year old music lessons?

All of these questions begin to establish a starting point for analysis of the photographs and their role in reflective practice. They are by no means the only questions that could be used when looking at one's self in the context of reflective practice; they are however, a beginning. Visual narrative, the photographs and the stories behind these images, provide a differing perspective to the thoughts and ideas that flag our mind and allow for the self-assessment and monitoring of our practice in a productive way that allows for all in the classroom to be learners. We as teachers can be provided with an opportunity to see things we perhaps missed or did not realize was going on during a lesson an in turn have a reminder that allows for further follow-up and exploration.

FINAL EDITS_Take a photography, N.Lemon (2007) The University of Melbourne, page 13 


\section{Hanging the photograph: Where to next?}

The journey of visually narrating my professional development has made me come to one quite big realization, for the first time in my teaching career I believe I have been the most relaxed and content. I have become more comfortable in myself, which has lead to me becoming more comfortable in working with children. That is not to say that I was awkward, unprofessional, nor approached teaching 'flying by the seat of my pants' or not participating in reflective practice. It is more a philosophical realization that this year I have developed through my journey of teaching. I have for the first time felt comfortable in my understandings of curriculum and its place in educational environments. More importantly, I can see where I fit into the educational environment. And my visual journey, although sometimes confrontational, like questioning myself and trying to find answers to questions about my professional practice and learning, but often rewarding, like finding those answers, has leaded me to the place I am at now. This discovering has leaded me to legitimately say I love teaching, and most importantly I know it and believe it too. I love the interaction with children. I love to see their engagement. I love to listen to their questions. And even more I love being a part of their learning journey. I have learnt so much how others learn, and in turn I have learnt a lot about myself.

'Issues of identity are at the heart of teaching and learning'.

(Moss et al, 2004, pp 10)

My own professional development and reflective practice has never been so active as this year. The power of visual narrative has taken me on a reflective journey, one where I feel like I have found myself, and my place within education. Although many questions are still unanswered in the use of visual narrative as a tool for reflective practice, I am even more than ever motivated to continue my own learning journey through exploring this methodology in the role of teacher reflective practice; where a window is being opened for meaning making of our learning journey, one full of challenges, self questioning but creations of understanding, knowledge, motivation and engagement.

FINAL EDITS_Take a photography, N.Lemon (2007) The University of Melbourne, page 14 


\section{Resources:}

Bach, H. (1998). A visual narrative concerning curriculum, girls, photography etc. University of Alberta: Qual Institute Press.

Bach, H. (2001). The place of the photograph in visual narrative research-project Statement. Retrieved 4 November, 2004, from http://www.findarticles.com /p/articles/mi_m2479/is_3_29/ai_80757500/print.

Bager-Charleson, S. (2004). The parents' school? Narrative research about parental involvement in schools. Retrieved 24 August, 2004, from http://www.lse.ac.uk/ Collections/genderInstitute/events/postgraduateSeminars/January.html.

Berger, J. (1980). About Looking. London: Writer and Readers Publishing.

Bruner, J. (1990). Acts of meaning. Cambridge: Harvard University Press.

Brookfield, S. D. (1995). Becoming a critically reflective teacher. San Francisco: JosseyBass Publishers.

Calderhead, J. (1989). Reflective teaching and teacher education. Teaching and Teacher Education, 5 (1), 43 - 51.

Clandinin, D. J. \& Connelly, F. M. (2000). Narrative inquiry: Experience and story in qualitative research. San Francisco : Jossey-Bass.

Clough, P. (2002). Doing qualitative research in educational settings: Narratives and fictions in educational research. Buckingham: Open University Press.

Daiute, C., \& Lightfoot, C. (2004). Editors introduction: Theory and craft in narrative inquiry. In Daiute, C., \& Lightfoot, C. (Eds.). Narrative analysis: Studying the development of individuals in society. (Pp vii - xviii ). Thousand Oaks: Sage Publications.

Dewey, J. (1929). Democracy and education; an introduction to the philosophy of education. New York: The Macmillan Company.

Diekelmann, N. (2005). Engaging the student and the teacher: Co-Creating substantive reform with narrative pedagogy. Journal of Nursing Education. 44 (6), 249 251.

Florio-Ruane, S. (2001). Teacher education and the cultural imagination: Autobiography, conversation and narrative. London: Lawrence Erlbaum Associates Publishers.

Fredidus, H. (1998, April). Narrative practices: Portfolios in teacher education. Paper

FINAL EDITS_Take a photography, N.Lemon (2007) The University of Melbourne, page 15 
presented at the Annual Meeting of the American Educational Research Association. San Diego, C.A.

Gawehen, C. (2003). E-Portfolio of Teaching. Retrieved 18 March, 2004, from http://golum.riv.csu.edu.au/ cgaweh01/index.html.

Grimmett, P., MacKinnon, A., Erickson, G., \& Riecken, T. (1990). Reflective practice in teacher education. In R. Clift, W.R. Houston, \& M. Pugach (Eds.), Encouraging reflective practice in education. (pp 20-38). New York: Teachers College Press.

Jay, J. K. (2003). Quality teaching: Reflection - The heart of practice. London: Oxford.

Johnson, G. (2001). Teacher reflection narratives: a poststructural approach. Journal of Education for Teaching, 27 (2), $199-200$.

Kramp, M.K. (2004). Exploring life and experience through narrative inquiry. In K.B. DeMarrais \& S.D. Lapan (Eds.), Foundations for research: Methods of inquiry in education and the social sciences - Inquiry and pedagogy across diverse contexts (pp 104 - 121). Mahwah: N.J. Lawrence Erlbaum Associates Inc.

Lieblich, A., Tuval-Mashiach, R. \& Zilber, T. (1998). Narrative research: Reading, analysis, and interpretation. Thousand Oaks: Sage publications.

Loughren, J. J. (1996). Developing reflective practice. London: Farmer Press.

Moss, J. (2003). Picture this: visual narrative as a source for understanding diversity in our classrooms. Melbourne: Festival against Racism in Education.

Moss, J., Dixon, M., English, R., Ferguson, P., Godinho, S., Hay, T., Longaretti, L., Sanjakdar, F., White, J., \& Wilson, J. (2004). Invitations \& inspirations:

Pathways to successful teaching. Melbourne: Curriculum Corporation.

Nelson, K. (2004). Construction of the cultural self in early narratives. In

Daiute, C., \& Lightfoot, C. (Eds.). Narrative analysis: Studying the development of individuals in society. (pp $87-109$ ). Thousand Oaks: Sage Publications.

Polkinghorne, D. E. (1988). Narrative knowing and the human sciences. Albany: State University of New York Press.

Richardson, L. (1990). Writing strategies: Reaching diverse audiences. London: Sage Publications.

Sabin, T. R. (2004). The role of imagination in narrative construction. In

Daiute, C., \& Lightfoot, C. (Eds.). Narrative analysis: Studying the development of individuals in society. (pp $5-20$ ). Thousand Oaks: Sage Publications.

FINAL EDITS_Take a photography, N.Lemon (2007) The University of Melbourne, page 16 
Schwarz, G. (2001). Using teacher narrative research in teacher development. The Teacher Educator, 37 (1), 37 - 48.

Spence, D.P. (1986). Narrative smoothing and clinical wisdom. In T.R.Sarbin (Ed.). Narrative psychology: The stories nature of human conduct. (pp. $211-232$ ). New York: Praeger.

Stronge, J. H. (c2002). Qualities of effective teachers. Virginia, USA: Virginia Press Inc.

Verhesschen, P. (1999, April). Narrative research and the concern with the truth. Paper presented at the Annual Meeting of the American Educational Research Association. Montreal, Canada.

Wilson, J. \& Wing Jan, L. (1993). Thinking for themselves: Developing strategies for reflective learning. Armadale, Australia: Eleanor Curtain Publishing.

Wood, D. R. (2000). Review of 'Narrative inquiry: Experience and story in qualitative research'. Retrieved 24 August, 2004, from http://www.aaanet.org/ cae/aeq/br/clandinin.htm.

Young, S. (2003). Music with the under-fours. London: Routledge-Falmer.

Zeichner, K. M. (1994). Conceptions of reflective practice in teaching and teacher education. In G. Rees Harvard, \& P. Hodkinson (Eds.), Action and reflection in teacher education. (pp15 - 34). Norwood, New Jersey: Ablex Publishing Corporation.

FINAL EDITS_Take a photography, N.Lemon (2007) The University of Melbourne, page 17 